\title{
Ideologia, divisão capitalista do trabalho e papel social do designer: um estudo sobre a produção de materialidade no design de moda
}

Ideology, capitalist division of labour and social role of the designer: a study on the production of materiality in fashion design

Joana Martins Contino

Doutoranda na PUC-Rio joanacontino@hotmail.com

Alberto Cipiniuk 


\section{Ideologia, divisão capitalista do trabalho e papel social do designer: um estudo sobre a produção de materialidade no design de moda}

Ideology, capitalist division of labour and social role of the designer: a study on the production of materiality in fashion design

Joana Martins Contino e Alberto Cipiniuk

\section{Resumo}

Visando debater acerca da divisão social do trabalho e de como ela se manifesta no Campo do Design de Moda, além do papel social do designer de moda na cadeia produtiva, o presente artigo apresenta duas noções antagônicas que visam explicar importantes transformações ocorridas na sociedade industrial na segunda metade do século XX: "sociedade pós-industrial" do autor Daniel Bell, e "capitalismo tardio" de Ernst Mandel. Cada uma dessas teorias provém de distintos posicionamentos ideológicos e tem impacto no Campo do Design, tanto no que diz respeito à produção teórica quanto à formação e às práticas profissionais dos designers. Sendo assim, através de pesquisa bibliográfica, iniciamos $\mathrm{o}$ artigo com uma reflexão acerca da produção de materialidade e de imaterialidade no Design e, a seguir, confrontamos essas duas importantes correntes teóricas e as relacionamos a outras que entendemos ser decorrentes de uma delas - "fim do trabalho", "design enquanto processo" - e a questões objetivas e concretas de um dos ramos do design em que a produção material e o enorme contingente de trabalhadores são inegáveis: o Campo da Moda. Entre essas questões estão a divisão social do trabalho e a propagação da noção mítica de criador individual, inclusive reproduzida pelo sistema de ensino.

Palavras- chave: Design de Moda, Materialidade, "Sociedade Pós-industrial", "Capitalismo Tardio", Divisão do Trabalho.

\begin{abstract}
Aiming to discuss about social division of labour and how it appears in the fashion design field, in addition to debate about the social role of fashion designer in the production chain, this paper presents two opposing notions that aim to explain important changes that have occurred in industrial society in the second half of twentieth century: "post-industrial society" of the author Daniel Bell, and "late capitalism" from Ernst Mandel. Each of these theories come from different ideological positions and impacts on the field of design with regard to theoretical production and the professional qualification and practices of designers. Thus, through bibliographic research, we began this paper with a reflection on the materiality and immateriality production in design. Then we confront these two important theoretical currents and relate them to others that we believe to be arising from one of them - "end of work", "design as a process" - and to objective and concrete issues of one of the design branches in which material production and the huge number of workers are undeniable: the fashion design field. Among these issues are the social division of labour and the propagation of the mythical notion of the individual creator, even propagated by the education system.
\end{abstract}

Keywords: Fashion Design, Materiality, "Post-industrial society", "Late Capitalism", Labour Division. 


\section{INTRODUÇÃO}

Na segunda metade do século XX, ocorreu uma revolução fundamental na tecnologia, na organização do trabalho e nas relações de produção que modificou a configuração da sociedade industrial. Houve enorme expansão da capacidade produtiva através do aumento da automação na indústria. Consequentemente, em diversos setores industriais houve diminuição de força de trabalho empregada e o setor de serviços sofreu uma gigantesca ampliação. Essas transformações ocasionaram o surgimento de teorias que visam explicar a natureza das mudanças.

Neste artigo, apresentamos duas correntes distintas e antagônicas: a que defende que vivemos em uma "sociedade pós-industrial" de Daniel Bell (1977) e a do “capitalismo tardio" de Ernst Mandel (1982). Cada uma delas decorre de ideologias distintas. Entendendo o conceito de ideologia como "processo material geral de produção de ideias, crenças e valores na vida social" (EAGLETON, 1997:38), constatamos que essas teorias sobre a sociedade têm impacto no campo do design, tanto no que diz respeito à produção teórica quanto à formação e às práticas profissionais dos designers.

Sendo assim, através de pesquisa bibliográfica, buscamos confrontar essas duas meritórias correntes teóricas - "sociedade pós-industrial", "capitalismo tardio" - e relacioná-las a outras que entendemos ser decorrentes de uma delas - "fim do trabalho", "design enquanto processo" - e a questões objetivas e concretas de um dos ramos do design em que a produção material e o enorme contingente de trabalhadores são inegáveis: o Campo da Moda. A seguir, refletimos sobre divisão social do trabalho e a propagação da noção de criador individual, inclusive pelo sistema de ensino, e o papel social do designer na cadeia produtiva.

\section{MATERIAL VERSUS IMATERIAL NO DESIGN}

Atualmente, a antiga noção segundo a qual a principal atribuição do designer seria a concepção de objetos industriais ou o embelezamento deles parece ter caído em desuso no campo. De acordo com uma das definições de design em voga, ele é um processo e não mais uma coisa que eventualmente poderíamos pegar com as mãos. Sendo assim, o design é um sistema, um modo de pensar (AMBROSE; HARRYS, 2011). 
Mas, assim como a definição "antiga" não dá conta da complexidade das competências dos designers nos dias atuais - como indicam as diversas nomenclaturas empregadas no campo que buscam definir possíveis distintas áreas nele, tais como design emocional, de experiência, de serviços, de interfaces, entre outras -, a "nova" também não nos parece adequada. A afirmação que o design é um processo, algo que não se pode tocar, ou seja, é imaterial, implica em aceitar a ideia de que atualmente a prática do design é, sobretudo, produzir imaterialidades, por exemplo serviços e interfaces digitais.

Essa concepção, que tem grande aceitação no campo, supervaloriza o imaterial e parece não dar a devida importância ao fato de que essa imaterialidade está contida na materialidade. Na verdade, sua ocorrência só é possível a partir do material: um serviço, um site ou um jogo de computador são materiais, já que eles só podem existir amparados por um suporte concreto e físico. Afinal, não se pode utilizar um jogo virtual sem um computador ou telefone celular. Ou, dizendo de outro modo, a existência desses produtos "que não se podem pegar com as mãos" só pode ocorrer em certas condições materiais de produção. A imaterialidade é, portanto, efeito do material. E não o contrário, como parece indicar essa corrente de interpretação do design que advoga acriticamente pela extinção do que poderíamos considerar sua base ontológica, ou seja, a produção material na sociedade capitalista.

Indo em sentido diferente a ela, concordamos com a percepção de Adrian Forty, que aponta que o design é uma atividade mais significativa do que costuma enunciar, especialmente no que diz respeito a aspectos econômicos e ideológicos, pois historicamente está ligado ao lucro empresarial e à transmissão de ideias (2007: 11).

Assim, entendendo o design como "algo incontornavelmente cultural e ideológico" (CIPINIUK, 2014: 60), nos parece que a ênfase na "imaterialidade" do design tem relação direta com um conceito muito mais amplo que é aceito por uma parcela considerável de teóricos, impactando diversas correntes de pensamento das ciências humanas e sociais: a noção de "sociedade pós-industrial". O termo cunhado por Daniel Bell (1977) e as teorias correlatas a essa nomenclatura procuram demonstrar que haveria uma nova forma social que não obedeceria às leis do capitalismo clássico, tais como a primazia da produção industrial e a onipresença da luta de classes (JAMESON, 1997: 29). 
De acordo com a tese apresentada pelo sociólogo norte-americano no seu famoso livro $O$ advento da sociedade pós-industrial, nos trinta ou cinquenta anos subsequentes ao seu lançamento em 1973, ocorreria uma mudança crucial na estrutura social dos países industrializados. No setor econômico, haveria uma transposição da manufatura para os serviços; em relação à tecnologia, a sociedade pós-industrial se caracterizaria pela centralidade das avançadas indústrias com bases científicas; e, em termos sociológicos, haveria a ascensão de novas elites técnicas e o advento de um novo princípio de estratificação (BELL, 1977: 538). Com essa mudança estrutural, a fonte de poder viria da informação. Então, haveria a centralidade do conhecimento teórico e a primazia da teoria sobre o empirismo. Para o autor, toda a sociedade viveria pela inovação e desenvolvimento e o conhecimento teórico seria a matriz da inovação (BELL, 1977: 380).

A posição que defendemos é outra: assim como Mandel (1982), não denominamos o atual momento histórico de "pós-industrial", mas sim de capitalismo tardio e não o consideramos como uma fase inteiramente nova do desenvolvimento capitalista, mas como desdobramento histórico desse modo de produção, portanto, continuação da fase anterior, o capitalismo monopolista. $\mathrm{O}$ economista belga situa o início do capitalismo tardio após o fim da Segunda Guerra Mundial, em 1945, e, para ele, as leis básicas do movimento capitalista continuam em ação, como o papel central da teoria do valor-trabalho ${ }^{1}$, a tendência à concentração e centralização de capitais, entre outras. Partilhamos do ponto de vista do autor que sustenta que no capitalismo tardio, pela primeira vez na história, todos os ramos da economia se encontram plenamente industrializados e que a automação provocou, nas últimas décadas, um aumento extraordinário da produtividade do trabalho. Todos os setores da vida social são impactados pela mecanização:

Uma das características do capitalismo tardio é que a agricultura está se tornando gradualmente tão industrializada quanto a própria indústria, a esfera da circulação tanto quanto a esfera da produção, o lazer tanto quanto a organização do trabalho. A industrialização da esfera da reprodução constitui o ápice desse processo (MANDEL, 1982: 271-272).

Nesse sentido, o autor afirma ainda que a tão propagada noção de "sociedade pós-industrial" e a crença na onipotência da tecnologia são formas de manifestação da ideologia apologética da manutenção do modo de produção capitalista (MANDEL,

\footnotetext{
1 Segundo a teoria do valor-trabalho, a fonte de riqueza social é o trabalho humano. Para Marx, o que determina o valor de troca das mercadorias é o tempo de trabalho socialmente necessário à sua produção.
} 
1982: 351). A aceitação da noção de que vivemos numa "sociedade pós-industrial" tem consequências práticas e políticas, entre elas a disseminação da ideia de que, assim como haveria desaparecido a produção industrial convencional, não existiriam mais as classes sociais do tipo clássico. Além disso, o "apagamento dos traços da produção" retira dos consumidores a percepção de que o trabalho de outros seres humanos foi necessário para que seus bens fossem produzidos (JAMESON, 1997: 78 e 318).

No que diz respeito ao apagamento dos traços da produção industrial, é preciso mencionar a teoria do "fim do trabalho", intimamente ligada à noção de "sociedade pósindustrial". Segundo essa corrente teórica, na sociedade contemporânea, o trabalho teria perdido a centralidade. A popularização dessa tese é frequentemente atribuída a Gorz (1982 apud CARCANHOLO; MEDEIROS, 2008), que alega que o crescimento do setor de serviços desqualifica a categoria de trabalho produtivo. Além disso, o autor sustenta que a revolução tecnológica e a consequente informatização dos processos produtivos fariam com que o trabalho perdesse sua preponderância na produção material.

A tese do "fim do trabalho" surge, objetivamente, graças a intensos avanços tecnológicos em boa parte das indústrias (sobretudo nos países centrais) que provocaram intensa automação na produção. Mas ela tem sua origem também em equívocos na compreensão e emprego de alguns conceitos-chave da teoria marxiana. $\mathrm{O}$ primeiro deles diz respeito à noção de trabalho concreto, que para Marx é "a atividade mediante a qual a espécie humana cria, em dado grau de desenvolvimento social, as suas condições de existência", ou seja, "toda e qualquer atividade que integra a divisão social do trabalho é trabalho, seja uma atividade industrial ou não" (CARCANHOLO. MEDEIROS, 2008: 180). Esse erro de compreensão contribui para outra confusão conceitual: a respeito do que é trabalho produtivo e improdutivo. O primeiro é qualquer atividade que propicia a valorização do capital. E vale ressaltar que, "em momento algum e de nenhuma forma, Marx sugere que só valem como formadores de valor determinadas formas concretas de trabalho, isto é, aquelas que criam mercadorias, digamos, tangíveis" (CARCANHOLO; MEDEIROS, 2008: 181).

Voltando ao design, sabemos que seu surgimento enquanto campo de atuação profissional tem relação direta com o desenvolvimento do capitalismo industrial (FORTY, 2007), ou seja, com o aumento da produção de mercadorias tangíveis. Desse 
modo, não podemos considerar uma "coincidência" que, justamente quando há um esforço teórico no sentido de negar a produção industrial convencional, haja também supervalorização do lado "imaterial" do design por uma parcela considerável do corpus teórico do campo ${ }^{2}$. Tratar a produção do design que, como já foi salientado acima, prescinde do material como sendo algo imaterial oculta não só a indispensabilidade dos meios de produção como também ajuda a apagar o trabalho humano por trás dos produtos e serviços que consumimos.

Em alguns ramos de atuação do profissional de design é mais fácil negar a materialidade da produção - como o design de interfaces digitais e de serviços, já citados acima - tendo em vista o resultado, ou seja, o produto considerado "imaterial", decorrente dos processos de produção neles empregados. No entanto, a produção e comercialização de mercadorias tangíveis é o propósito de muitos setores em que designers trabalham, entre eles podemos citar a indústria moveleira e a indústria da moda, esta última, objeto de análise no presente artigo.

\subsection{Indústria da moda e a materialidade}

A razão de ser da indústria da moda não é produzir roupas, bolsas e sapatos, mas produzir matérias-primas (sobretudo tecidos) que são fornecidas a outros produtores, que, por sua vez, fabricam roupas e acessórios que são vendidos a empresas ou diretamente aos consumidores. Ainda que se possa argumentar que o campo de atuação do designer de moda também contempla a oferta de serviços, a divulgação de informações em plataformas digitais e outros produtos "imateriais", podemos facilmente perceber que todos eles têm a função de facilitar o escoamento da produção industrial. Essa facilitação pode estar diretamente ligada à venda (plataformas digitais de venda on-line, por exemplo) ou às instâncias de consagração do produto e do produtor, ou seja, da marca (como os blogs de moda). Em última análise, o "imaterial" existe em função de estimular o consumo de mercadorias tangíveis que são produzidas nas muitas fábricas e confecções mundo afora. Desse modo, parece-nos que é impossível negar a materialidade da produção no Campo do Design de Moda.

\footnotetext{
${ }^{2}$ Cf. por exemplo:

DIANI, Marco. Immateriality takes Command. In Design Issues: Vol. IV, Numbers 1 \& 2, 1988. MOLES, Abraham A; JACOBUS, David W. Design and Immateriality: What of It in a Post Industrial Society? In. Design Issues: Vol. IV, Numbers 1 \& 2, 1988.
} 
A moda é um setor industrial de grande importância econômica ${ }^{3}$. Estima-se que hoje no mundo haja em torno de quarenta milhões de pessoas trabalhando na indústria de confecção (SIEGLE, 2011: 40). No ano de 2010 na China, a maior produtora mundial de artigos têxteis e de vestuário, havia 11.201.100 trabalhadores formais envolvidos na fabricação de tecidos e roupas. No mesmo ano, no Brasil foram contabilizadas 979.511 pessoas contratadas formalmente na fabricação de artigos têxteis e de vestuário (OIT, 2013: 9). Segundo a ABIT (2011), no Brasil há aproximadamente 30 mil empresas nos setores, que geram mais de oito milhões de empregos diretos e indiretos.

A grandiosidade dos números se dá porque, especialmente no setor de confecção de vestuário, apesar do aumento da velocidade de execução das tarefas ocasionado pelo desenvolvimento tecnológico, o binômio um homem/uma máquina ainda não foi superado, ou seja, a tese de Bell que pressupõe uma "sociedade pós-industrial" é uma falácia. Junto a cada máquina em funcionamento há um ser humano com maior ou menor habilidade executando as tarefas que lhe cabem na montagem de uma roupa. Esse é, portanto, um setor intensivo em força de trabalho. A análise das relações de trabalho no interior da indústria da moda nos oferece subsídios para contestar a tese do fim do trabalho. Apesar de utilização de maquinaria de última geração, nessa indústria é imprescindível o trabalho humano e manual - trabalho vivo.

Recentes transformações na indústria da moda ocorridas no capitalismo tardio alteraram profundamente a circulação dos produtos têxteis ${ }^{4}$. De algumas décadas para cá, a velocidade de produção e a quantidade de coleções anuais apresentadas ao público aumentou muito, o que transformou também as práticas de criação e desenvolvimento do produto. Houve um aumento na quantidade e velocidade de concepção dos novos modelos, o que engendrou uma nova dinâmica projetual. As mudanças implicam também em alterações no funcionamento das diferentes esferas da longa cadeia produtiva de vestuário. No âmbito interno às empresas, os setores criativo, produtivo, administrativo e comercial têm estabelecido novas maneiras de interação e atuação.

\footnotetext{
${ }^{3}$ Segundo relatório recente da OIT, em 2012 os setores de têxteis e de vestuário foram responsáveis por 4\% das exportações em nível mundial. Além disso, o relatório aponta muitas economias nacionais dependem economicamente do setor de confecção (OIT, 2014).

${ }^{4}$ Cf. CONTINO, Joana. Fast fashion: apontamentos sobre as transformações da moda na condição pósmoderna. Dissertação (mestrado) - Pontifícia Universidade Católica do Rio de Janeiro, Departamento de Artes e Design, 2015. Disponível em <http://www.dbd.pucrio.br/pergamum/biblioteca/php/mostrateses.php?open=1\&arqtese=1312286_2015_Indice.html >.
} 
Externamente, as relações com a cadeia de fornecedores e com os próprios consumidores também vêm sendo alteradas.

Aparentemente o papel do designer na cadeia produtiva da moda ganhou maior importância e muitos autores consagrados no campo destacam o design do produto como o principal diferencial no sucesso das empresas ${ }^{5}$. No entanto, essas mudanças vêm ocorrendo paralelamente ao aumento da exploração e à crescente precarização das condições de trabalho dos profissionais encarregados do desenvolvimento de produtos. Mas, apesar das evidências desse aumento, pouco se comenta a esse respeito na literatura do Campo do Design. Por isso, uma compreensão do papel do designer nessa cadeia e das suas relações com os outros trabalhadores, assim como o debate acerca do aparato ideológico que sustenta a crença no seu papel de destaque são relevantes para o campo e para seus profissionais.

\subsection{A noção de criação individual e a divisão do trabalho}

Assim como no Campo da Arte e em outras áreas do design, no Campo da Moda é amplamente difundida a noção de criação individual. Segundo essa ideia, o designer seria o principal, senão o único responsável pela existência dos produtos de vestuário. Não é preciso muita investigação para observar que, na prática profissional, a concepção dos produtos é realizada em equipe. Mesmo antes da coleção ser idealizada, outros profissionais já trabalharam na elaboração das matérias-primas, tanto na concepção de estampas, cores e tipos de materiais, quanto na materialização de tecidos e aviamentos.

A noção de criação individual está fundamentada na divisão capitalista do trabalho. Ao mesmo tempo, essa noção reforça tal divisão, em que concepção e execução são momentos distintos que são realizados por diferentes trabalhadores. Tal separação tem consequências inevitáveis, por exemplo no que diz respeito à organização espacial: em um local são executados os processos produtivos propriamente ditos, em outro acontecem o projeto e o planejamento. Desse modo, as atividades produtivas são planejadas antes que o projeto seja posto em andamento e a concepção governa a execução. Os dois aspectos do trabalho, o manual e o intelectual, tornam-se, além de

\footnotetext{
${ }^{5}$ Cf. por exemplo CIETTA, Enrico. A revolução do fast fashion: estratégias e modelos organizados para competir nas indústrias híbridas. São Paulo: Estação das Letras e Cores, 2010.
} 
separados, hostis um ao outro, ainda que ambos sejam necessários à produção (BRAVERMAN, 1980).

A divisão manufatureira do trabalho é o "parcelamento dos processos implicados na feitura do produto em numerosas operações executadas por diferentes trabalhadores" (BRAVERMAN, 1981: 72). Com a divisão, o empregador pode comprar exatamente a quantidade de força de trabalho necessária para a realização de determinado processo e forçar para baixo seu valor.

Por um lado, o parcelamento leva o trabalhador a se especializar, aumentando sua produtividade devido à simplicidade do processo que repete. Mas há outro elemento importante: quando o trabalho é todo executado pela mesma pessoa, ela deve ser capaz de realizar todas as operações, desde a mais fácil até a mais difícil, desde a concepção até a execução. Desse modo, o profissional mantém o controle do processo de trabalho. Quando o trabalho é parcelado, as tarefas tornadas mais simples são designadas a profissionais com menos qualificação e que dependem inteiramente do empregador para realizar seu trabalho, pois não dispõem nem dos meios de produção nem do controle sobre o conjunto do processo, sendo facilmente intercambiáveis - como peças de reposição de uma máquina. O empregador, em condições a tal ponto vantajosas, despende menos pela execução de um processo que, ao final, produz o mesmo resultado. A divisão faz com que, para a realização de boa parte dos processos produtivos, conhecimento e preparo especial sejam dispensados e desvincula a concepção da execução. $\mathrm{O}$ fracionamento acaba assim por baratear a força de trabalho (BRAVERMAN, 1981: 70-80).

No âmbito do design de moda, observamos que o papel do designer "criador" é reforçado não só pelas instâncias de consagração que visam conferir maior "valor simbólico" às marcas e, consequentemente, aos produtos comercializados por elas, mas também pelo sistema educativo. Os alunos iniciantes já entram nas escolas de design crentes que isso que se denomina moda se baseia única e exclusivamente na "criação individual", uma vez que essa noção é amplamente divulgada por essas instâncias de consagração (as próprias escolas e os meios de comunicação), já que muitos dos profissionais de educação são também ligados ao "mercado", ou seja, ideologicamente também fazem parte desse circuito de consagração comprometido com o funcionamento do campo, por essa razão também creem na referida noção e a propagam. 
O designer de moda, de acordo com a noção de "criação individual" e, na maioria das vezes, também na sua prática profissional, é o responsável por conceber os produtos, mas não por executar sua produção. Portanto, boa parte dos alunos de design de moda considera alguns saberes como os relacionados à modelagem e à costura absolutamente supérfluos. Como consequência nota-se um desinteresse pelas disciplinas práticas e a pergunta "Por que preciso aprender isso se vou ser designer de moda?" é ouvida com frequência pelos professores. O trabalho intelectual - o de "pensar" a coleção - é valorizado e as disciplinas de projeto ganham destaque; enquanto o trabalho manual - a execução do projeto - é desvalorizado.

A respeito desse ponto, acreditamos que podemos localizá-lo paralelamente com aquilo que Daniel Bell chamou de "centralidade do conhecimento teórico" (1977: 380). Numa sociedade em que existe a predominância da teoria sobre a prática (ou o empirismo, termo utilizado pelo autor), por que seria necessário ter conhecimento acerca do processo global de trabalho?

Quando o estudante de design de moda ingressa no mercado de trabalho, se depara com um cotidiano profissional em que a divisão do trabalho é regra geral. Em um pequeno ateliê, pode até acontecer o fato de o designer conceber sozinho os produtos, mas essa noção também é mítica ${ }^{6}$ e, do mesmo modo, dificilmente ele poderia executar sua produção. Quando o faz, geralmente faz apenas parte dela, recorrendo à contratação de profissionais de costura para auxiliá-lo. Já numa empresa média, o desenvolvimento de produtos costuma ser realizado em equipe, podendo até mesmo haver diferentes equipes para os diferentes tipos de peças ${ }^{7}$. Geralmente esses grupos são compostos por profissionais dispostos hierarquicamente: chefes de equipe, assistentes de estilo, estagiários. Em geral, há ainda um estilista que está acima dos chefes de equipe, cuja função é coordenar o trabalho dos diversos grupos. Muitas vezes, esse coordenador é um dos proprietários da empresa.

Numa confecção, os setores são espacialmente separados. Mais ainda, as diferentes etapas do processo podem acontecer em empresas diferentes e até mesmo em

\footnotetext{
${ }^{6}$ Howard S. Becker, já havia demonstrado essa impossibilidade. Cf. BECKER, Howard S., Art Worlds. Berkeley, Los Angeles, London: University of California Press, 1984.

${ }^{7}$ Um exemplo de divisão de equipes de trabalho: um grupo de profissionais é responsável pelos produtos em jeans, outro é responsável por aqueles que serão fabricados em malha e uma terceira equipe é incumbida da criação das peças de tecido plano.
} 
diferentes lugares do mundo. Muitas vezes a concepção dos produtos acontece em um país e a execução deles ocorre em outro, onde a força de trabalho é mais barata.

Voltando à questão educacional, podemos nos perguntar por que o ensino das práticas do design de moda não corresponde à realidade da maior parte dos profissionais inseridos no mercado de trabalho, já que, apesar da divisão, eles não serão "criadores individuais". Nesse sentido é importante observar que as instituições de ensino de design são mais que locais de formação técnica, são também "espaços de recrutamento e capacitação simbólica para novos membros dessa categoria profissional” (CIPINIUK, 2014: 21). É nesse sentido que Alexandre Bergamo afirma que os indivíduos envolvidos com a criação procuram dar provas que o universo em que então inseridos é "privilegiado". As regras para consagração no campo são fluidas e se modificam com o tempo, mas isso não significa que elas não existam. Tais regras não se limitam a um conhecimento prático acerca do design de moda, é preciso que uma determinada grife ou “criador" prove que suas criações fazem parte desse universo de privilégios (2007: 102-103).

Se o trabalho intelectual (ou a concepção) é visto na sociedade como superior ao trabalho físico (ou a execução), nada mais natural, portanto, que o sistema de ensino superior, ou seja, faculdades e universidades que ensinam o design de moda, reforcem a ideia mítica de que seus alunos são privilegiados por fazerem parte desse universo criativo.

É importante ressaltar, entretanto, que na prática profissional o designer de moda não ocupa a posição central na qual ele crê durante seu aprendizado. A concepção governa a execução, por isso as funções manuais são consideradas, inclusive pelo designer, como sendo menores do que as intelectuais. Entretanto, assim como os profissionais das atividades de execução, ele também não tem domínio sobre o processo produtivo completo. $\mathrm{O}$ designer de moda sabe conceber, mas não consegue executar, o que acaba culminando numa desvalorização do seu próprio trabalho. O mito do "criador" ajuda a ocultar um fato importante: ambas as etapas do processo operam segundo a mesma lógica, cuja finalidade é baratear a produção através da desvalorização do trabalho. 


\section{CONCLUSÃO}

Finalmente, é importante esclarecer onde queremos chegar ao tratar de assuntos aparentemente tão distintos: o conceito de design enquanto "processo imaterial", a "sociedade pós-industrial" e a decorrente teoria do "fim do trabalho", a noção de “criação individual" e divisão capitalista do trabalho no design de moda.

O ponto é que, mesmo concebendo produtos industriais, ao seguir a ideologia dominante no campo e, portanto, ao "se diferenciar" dos demais profissionais pertencentes à cadeia produtiva - os responsáveis pela execução -, o designer se coloca "fora" e "acima" do processo produtivo como um todo, se põe no lado do "imaterial", do "não trabalho".

Aparentemente em um lugar de privilégio, já que estaria no topo da hierarquia da cadeia produtiva, na realidade, o profissional de criação está reproduzindo (com o estímulo das instituições de ensino) todo um aparato ideológico que visa manter e aumentar a base de sustentação do modo de produção capitalista: a exploração do trabalho. Essa exploração e a desvalorização do trabalho incidem nos trabalhadores que estão "abaixo" dele, mas, conforme explicitado anteriormente, também impactam no seu próprio trabalho.

Apesar do termo "pós-industrial" ser amplamente utilizado, nem todas as “previsões" de Bell (1977) se concretizaram. Continuamos vivendo numa sociedade industrial e a predominância da teoria sobre a prática é apenas aparente. Como vimos acima, a indústria de confecção é uma das que o trabalho vivo continua sendo imprescindível, por isso, mesmo com toda a tecnologia, são indispensáveis pessoas na produção das mercadorias que alimentam um enorme mercado de consumo. Sendo assim, através do exemplo do que ocorre nesse campo de atuação do profissional de design, observamos que o trabalho - tanto dos profissionais ligados à concepção quanto daqueles ligados à execução - continua sendo central na nossa sociedade.

Como bem salientou Lukács, a divisão social do trabalho é muito anterior ao atual modo de produção, mas, com o desenvolvimento deste, as consequências da divisão são muito difundidas e profundas. Nas suas palavras:

A divisão capitalista do trabalho, portanto, não se limita apenas a submeter a si todos os campos da atividade material e intelectual, mas se insinua profundamente na alma de cada um, provocando nela profundas 
deformações, que se revelam posteriormente sob várias formas nas diversas manifestações ideológicas (1981: 121).

É preciso, portanto, realizar um debate crítico acerca das questões levantadas neste trabalho de modo a estimular que o estudante de design, seja ele de moda ou de outras áreas do design, possa ter uma compreensão mais global do processo produtivo. Mais ainda, se o capitalismo requer a existência de elementos contraditórios que não podem haver um sem o outro, e, portanto, ele não é possível sem a existência simultânea do capital e do trabalho assalariado (MANDEL, 2015: 148), é preciso desvelar aos profissionais do campo e aos futuros designers seu papel social na estrutura produtiva. Afinal,

se se considera o trabalhador coletivo, de que a oficina consiste, sua atividade combinada se realiza materialmente e de maneira direta num produto total que, ao mesmo tempo, é um volume total de mercadorias; é absolutamente indiferente que a função de qual e tal trabalhador - simples elo desse trabalhador coletivo - esteja mais próxima ou mais distante do trabalho manual direto (MARX, 1978 apud ANTUNES, 2013: 127).

\section{REFERÊNCIAS}

AMBROSE, Gavin; HARRIS, Paul. Design Thinking. Porto Alegre: Bookman, 2011.

ANTUNES, Ricardo (org.). A dialética do trabalho: escritos de Marx e Engels. São Paulo: Expressão Popular, 2013.

ASSOCIAÇÃO BRASILEIRA DA INDÚSTRIA TÊXTIL E DE CONFECÇÃO (ABIT). Panorama do setor têxtil e de confecções. Brasília: ABIT, 2011. Disponível em <http://abit.org.br/abitonline/2011/06_07/apresentacao.pdf>. Acesso em 07 jan. 2016.

BELL, Daniel. O advento da sociedade pós-industrial. São Paulo: Cultrix, 1977.

BERGAMO, Alexandre. A experiência do status: roupa e moda na trama social. São Paulo: UNESP, 2007. 
BRAVERMAN, Harry. Trabalho e capital monopolista: a degradação do trabalho no século XX. Rio de Janeiro: Zahar, 1981.

CARCANHOLO, Marcelo Dias; MEDEIROS, João Leonardo. Trabalho no capitalismo contemporâneo: pelo fim das teorias do fim do trabalho. Revista Outubro. Niterói: UFF, 2012. Disponível em: <http://www.revistaoutubro.com.br/edicoes/20/out20_08.pdf>. Acesso em 01/05/2016.

CIPINIUK, Alberto. Design: o livro dos porquês: o campo do Design compreendido como produção social. Rio de Janeiro: PUC-Rio, 2014.

EAGLETON, Terry. Ideologia: uma introdução. São Paulo: UNESP: Boitempo, 1997.

FORTY, Adrian. Objetos de desejo: design e sociedade desde 1750. São Paulo: Cosac Naify, 2007.

JAMESON, Fredric. Pós-modernismo: a lógica cultural do capitalismo tardio. São Paulo: Ática, 1997.

LUKÁCS, Georg. Sociologia. São Paulo: Ática, 1981.

MANDEL, Ernest. O Capitalismo Tardio. São Paulo: Abril Cultural, 1982.

Introdução ao marxismo. Porto Alegre: Renascença, 2015.

ORGANIZAÇÃO INTERNACIONAL DO TRABALHO (OIT). Medir o progresso na luta contra o trabalho infantil: Estimativas e tendências mundiais 2000 - 2012. Genebra: Bureau Internacional do Trabalho, Programa Internacional para a Eliminação do Trabalho Infantil (IPEC), 2013. Disponível em <http://www.ilo.org/wcmsp5/groups/public/---ed_norm/--ipec/documents/publication/wcms_221799.pdf>. Acesso em 01/12/2015.

Salarios y tiempo de trabajo en los sectores de los textiles, el vestido, el cuero y el calzado: documento temático para el debate en el Foro de diálogo mundial sobre los salarios y el tiempo de trabajo en los sectores de los textiles, el vestido y el calzado. Genebra: Departamento de Actividades Sectoriales, 2014. Disponível em: $<$ http://www.ilo.org/wcmsp5/groups/public/---ed_dialogue/--sector/documents/publication/wcms_300643.pdf>. Acesso em 01/12/2015.

SIEGLE, Lucy. To die for: is fashion wearing out the world? Londres: Fourth Estate, 2011. 